\title{
FOREWORD
}

\section{Thomas C. Schelling}

What is impressive is not how complicated the idea of deterrence has become, and how carefully it has been refined and developed, but how slow the process has been, how vague the concepts still are, and how inelegant the current theory of deterrence is.

-Thomas C. Schelling, The Strategy of Conflict

DURING THE COLD WAR, the U.S. government was scandalously slow to learn, or at least to put into operation, the rudiments of deterrence. We must hope that learning how to deter terrorists may go more smoothly and more rapidly. I cannot tell just when that learning may have started; there is no obvious benchmark like Hiroshima, and there was no Pearl Harbor-like stimulus before 9/11. The comparison of progress post-Hiroshima and, say, post-9/11, is not very satisfying: the earlier problem was comparatively elementary, almost simplistic, compared with the chiaroscuro mess these authors have to deal with.

Furthermore, the post-Hiroshima era was not a history of successful deterrence. The North Koreans were not deterred in 1950. There is some hint that the North Koreans or their Soviet mentors took seriously a U.S. diplomatic statement that seemed to leave Korea out of the declared U.S. area of responsibility; still, they knew they were facing U.S. nuclear weapons. The People's Republic of China, that same year, was not deterred. North Vietnam was not. Egypt and Syria risked Israeli weapons in 1973. Argentina must not have bothered to consider British weapons in its ambitious campaign to recover the Falklands. Saddam Hussein was not afraid in 1991. Deterrence does not come without effort. Still, the one transcendent confrontation, between the USSR and the United States, or the Warsaw Pact and NATO, was a success (for both sides!). "Mutual deterrence" worked, and I would say quite comfortably after 1962. But mutuality was unique to that particular confrontation, until India and Pakistan entered such a relationship in the 1990 . 
But what a simple thing that was, that bilateral mutual relationship! Just two parties, fully identified, sophisticated and "rational," fully reciprocal, with nothing at stake worth a war, no real territorial threats, at least after 1962, no great technological secrets, good diplomatic communication, especially after the "hotline" of 1963.

The present situation is vastly more unfamiliar, uncertain, complicated. Multiple adversaries, multiple target nations, uncertain or unknown "addresses," multiple motives and motives in dispute, poor or nonexistent communications, some hostilities domestic, some transnational, no collaboration on anything like mutual deterrence, no confidence in any taboo (biological, nuclear), no confidence in "rationality," multiple vulnerabilities in population targets, potential financial and industrial targets, and people vulnerable to being terrified out of all proportion to actual experienced terrorist actions. And behind it all the possibility of nuclear or biological attacks on a scale to eclipse anything yet experienced. Whether any terrorist organization has recruited, or could recruit, the scientists and technicians required for any sort of nuclear enterprise may be dubious but not out of the question.

The chapters presented here cite a substantial literature that delves deeply into the study of deterrence and the study of terrorism. Their authors were under no obligation to coordinate or come to agreement. They did together undergo two days of intense presentation and conversation in the agreeable environment of Zurich, Switzerland, and to a greater or lesser extent revised their contributions. But you will find disagreement-not expressed disagreement, but presentations that at some points are alternative or even contradictory. You have to make up your own mind. It was my privilege not only to participate in the conference at the ETH Zurich but to review the final manuscript, not as editor but as preparation for this foreword. I can assure you this is a challenging collection, one especially valuable for its variety. 